\title{
AS CANTIGAS D'ESCÁRNIO E MALDIZER
}

\section{Affonso Robl -}

Afigura-se, à primeirá vista, paradoxal o ethos da poesia irovadoresca. Como é que um trovador do estofo lírico de um João Garcia de Guilhade - o poeta irremediavelmente ensandecido pelos olhos verdes da amada (CA 229) ${ }^{1}$ - pôde descer às chocarrices tão fesceninas endereçadas às soldadeiras Elvira Lopes e dona Ouroana (LAPA) 205,206 e 213)? ${ }^{2}$
Diz Segismundo Spina:
Para uma análise serena da poesia trovadoresca euro- péia, precisamos, antes de tudo, despojar-nos de certos preconceitos da vida moderna, que perturbam o nosso espirito crítico na compreensão da realidade ética dessa poesia. As formas de vida, sobretudo, a intensidade dra- mática com que a sociedede medieval dessa época vivia, diferem visceralmente do nosso modus vivendi, cujas di- mensões e profundidade estão muito longe daquele pa. thos da vida medieval de que fala Huizinga: ${ }^{3}$

Importa não perder de vista o caráter dualístico que empresta uma aparente contradição ao trovadorismo medieval. De um lado, a homenagem tributada a senhoras de alta linhagem, a mesura, a idéia de que beleza da amada é graça divina, o amor considerado essencialmente como um serviço, o lirismo escolástico, o servus em extase amoroso perante a domina, que lançam suas ralzes no idealismo platônico e cristão, e no maniqueísmo cátaro: a sublimação da. mulher. Do outro lado, a inebrieção dos sentidos, o desejo ardente da posse, o amor sensual que persegue implacavelmente o jazer (lat. iacere) e o jauzir (lat. gaudere), lirismo ancorado na erótica naturalista de Ovídio. O termo mesura (lat. mensura) denota "moderação", "equilibrio das atitudes e paixōes", 'domínio de si": "La mesura les fará que obren de las cosas como deven, e non passen

1 As indicaçues CA no texto referem-se a obra de vasconcelos, C. M. Cancioneiro da Ajudn. Fd. eritica e comentada. Hulle, M. Niemeyer, 1904.

2 A abreviatura LAPA referese no livro de LAPA, M. R. Cantigan d'escarnio - de mal dizer dos cancioneiros galego-portagnenes. 2 ed. Viko. Ed. Falaxin, 1970.

5 SPINA, Segismundo. O "razer bem" dos cantares trovadorescos. Revista Brasiloira do Filolozin, Rio de Janeiro, 2:185-6, dez. 1956. 
a mas." "Implica também na "cortesia.", "discrição", "bondade". Medievalização da sophosyne piatônica e da mesotes arisiotélica (e não da ascese cristã), mesura é conceito trovadoresco moral e estético, ao mesmo temp̃o; sem virtude não existe autêntica cortesia, mas esta deverá inspirar-se na alegria (joi) causada pelo êxtase contemplativo da beleza e do honra (prez) da dama - personificação óa virtude. No entanto, mostra-se extremamente fugidio o sentido da joi trovadoresca: oscila entre a "alegria", a "euforia espiritual" e a "idéia" ou até o "fáto da fruiçāo amorosa", mas que não pretende permanecer apenas no terreno subjetivo...

Consiste, pois, o amor cortês, que não deve ser confundido com - amor arturiano e cavalheiresco, na delicadeza, no refinamento da arte de amar, numa terna e respeitosa emoção provocada tão so. niente pelo pensamento da mulher amada, promovida moral $\in$ poetıcamente à categoria da dona; consiste na idéia de que o amor é, em si mesmo, fonte de valor, se não de virtude. E preciso, contuco, frisar bem que esse amor dos trovadores é concomitantemente etéreo e terreno, platônico e sensual. $O$ amor arturiano designa, por sua vez, a fusão do amor e da, magia, a exploração do sobre-humano (realiza-se num mundo maravilhoso), o estado de encantamento amoroso. Reserva-se a expressão amor cavalheiresco à galanteria heróica, generosa, extravagante por vezes, que os cavaleiros andantes prestavam às demoiselles e às damas. 5

Para Frappier, no fine amor, que é a nuança mais refinada do amor cortês, nāo há oposição fundámental entre a paixão e o amor, entre a carne e o espírito. Há, sim, presença simultânea, coexistência, consubstanciação do desejo carnal e da sublimação. E o fine amor um composto indisolúvel, um todo global, em que se fundem carne, coração e espírito, e donde se irradia um encantamento produzido pelo pensamento constante da dama, pela obsessão de sua imagem: fonte de alegria no próprio seio da tristeza; e a "sacralização" (união do desejo erótico com uma espécie de fervor religioso) de um amor em princípio adúltero, subjetiva ou até objetivamente. Ressalte-se, todavia, que o fine amor idealizava-se, espiritualizava-se cada vez mais, devido a contingências históricas (po: exemplo, a cruzada contra os altigenses) e, sobretudo, à religiäo cristã e feudal (v.g., o culto à Virgem Maria). ${ }^{\circ}$

\footnotetext{
4 ALFONSO X. el Sábio. Las siete partidas: cotejadas con varios códeces antiguos por Ia Real Academia de la Historia. Madrid, Impr. Real, 1807. pt. 2, t. 21, lel V.

5 Cf. ,FRAPPIER, Jean. Sur un procès fait à l'amour courteois. Romania, Paris $93(2): 190,1973$.

6 Cf. FRAPPIER, D. 166 e 192.
} 
"O trovadorismo - afirma Henning Brinkmann - alimenta-se de duas fontes: o pensamento e sentimento cristãos, na forma que lhes deu a tradição poética de Angers, e a tendência mundanal e erótica representada nos vagantes ou goliardos. /.../ A ambas correspondem duas concepções: amor princípio de elevação moral; amor, impulso dos sentidos". "

Esta segunda faceta da poesia medieval, o reverso da medalha lírica, traz-nos à mente as chocantes gárgulas que coroam as etéreas catedrais. Caem as flores da avelaneira e as folhas do verde pinho, deixando em seu lugar nua, mas sincera, a árvore da poesia lusitana. Ademais, consoante a poética tradicional, poesia é forma que colima a expressão dos sentimentos, quer amorosos quer coléricos ou irônicos. Aliás, toda a literatura portuguesa oscila, grosso modo, entre dois pólos extremos: o lirismo de raiz, diáfano, delicado (por vezes, encharcado de pieguice e morbidez), e i sentimento hipercrítico, sarcástico, desbragado. Entretanto, não são antagônicas essas atitudes, pois todo sarcástico, bem no íntimo, não passa de um sentimental. Note-se além disso que, sendo arte e não essencialmente poesia, a sátira trovadoresca permitia-se muite substância apoética.

Poesia satírica é composição em verso que procura ridicularizar os vícios e as deficiências de pessoas e épocas. Encerra um conteúdo jocoso, zombeteiro, ou sarcástico, atingindo às vezes a indignação e a revolta. Geralmente, o humor e a sátira correm fundidos em simbiose, mas em determinados casos torna-se possível separar um do outro. Humor é gracejo benevolente; o sentimento do risível num fundo de simpatia e compaixão. A sátira, ao contrário, constitui zombaria ultrajante, dura, sem caridade; é o sentimento do ridículo num fundo de antipatia.

A sótira foi cultivada pelos gregos nas poesias de agressão pessoal e nas comédias. São muito conhecidos os versos jâmbicos ce Arquíloco: "Archilochum proprio rabies armavit iambo", diz Horácio, na sua Epistola ad Pisones. Aliás, o metro jâmbico, ao mesmo tempo, vivo, enérgico e agressivo, presta-se admiravelmente à sátira. Mas é em Roma que o gênero satírico adquire toda a sua pujança. O pragmatismo dos romanos, seu gosto pela observação moral e pela chacota criaram a sátira, que teve em Lucílio o seu frimeiro representante ilustre, para depois firmar-se definitivamente

7 Citado por LAPA, M. Rodrigues, Liçōes de literatura portuguesa; época medieval. 8. ed. Coimbra, Coimbra Ed., 1970. D. 71-2. 
nas obras de Horácio, Marcial, Juvenal e Pérsio, a ponto de Quintiilano afirmar, com evidente exagero: "Satira quidem toto nostra est".

Herdeiros da graça céltica e latina, tornaram-se os galego-portugueses eximios mestres na chaiaça. Num de seus descordos, testemunhou Martim Moxa, trovador aragonês, a proclividade escarninha do povo luso-gaiaico:

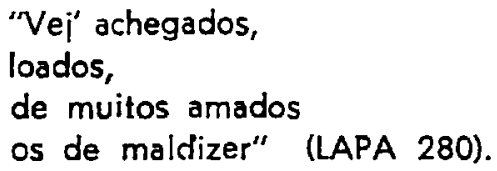

Essa atitude procaz dos nossos avoengos vem corroborada a saciedade pelas diversas palavras ou expressōes designativas do conceito "falar mal de alguém", correntes no séc. XIII: apoor, chu. far, desdizer, escarnecer, escarnir, posfaçar ou profaçar, travar, fazer jogo, dizer coblas ou cobras... (Esta última expressão significa propriamente "satirizar em versos"; cobras foi tomado, mais tarde, na acepção de "serpentes", uma vez que a. sátira não está longe da língua viperina).

As cantigas d'escárnio e maldizer constituem considerável par te dos nossos cancioneros medievais. Das 431 cantigas do terceiro gênero trovadoresco publicadas por Rodrigues lapa na monumental obra Cantigas d'escarnho e de mal dizer dos cancioneiros medievais galego-portugueses, 288 constam igualmente no Cancioneiro da Biblioteca Nacional e no Cancioneiro da Vaticana, 92 encontramse somente no CBN, 50 fazem parte do CV e uma (misto de cantar d'amigo e de maldizer) foi extraida do Cancioneiro da Ajuda. Essas composições escarninhas teriam formado, na opinião de Carolina Michaëlis de Vasconcelos, o prístino Cancioneiro de burlas, no qual as originais viriam acompanhados de notação musical. ${ }^{8}$

Destacam-se vários planos em nossos versos de chufa medievais. Nos seis capítulos que restaram da sua terceira parte, a Arte de trovar, apensa ao CBN, teoriza esmiuçadamente sobre as modalidades do gênero satírico. As cantigas d'escárnio eram veladas, indiretas, impessoais:

"Son aquelas que os trobadores fazen querendo dizer mal d'algué(n) en elas, e dizen-lho per palavras cubertas, que hajan duos entendimentos pera lhe lo non entenderen $/ . . . /$ ligeiramente; e estas palavras chamam

8 Cf. CA v. 2, D. 1 e 286. 
os clérigos hequivocatio (por aequivocatio). E estas cantigas se poden fazer outrossi de maestria ou de refran" (cap. V).

Nas cantigas de maldizer (espécie à que pertence a maioria das nossas poesias satíricas) atacava-se a descoberto, diretamente; nelas, diria eu vulgarmente, dava-se o nome oos bois, isto é, chomavam-se as pessoas e as coisas pelo seu nome:

"Son aquelas - diz o fragmentário trałado métrico - que
fazen os trobadores mais descobertamente; en elas entran
palavras que queren dizer mal e non haver <án> outro
entendimento senon aquel que queren chãamen <te>
e outrossi a todos fazen dizer mais" (cap. IV).

Portanto, nas cantigas d'escárnio, o ataque, velado sob formas smbíguas̄, magoava de leve, ao passo que nas de maldizer a ofensa direta, sem artificios, vazada em termos baixos e dícazes, feria brutalmente. Todavia, nem sempre é fácil fazer tal distinção, devido à freqüiente concorrência do equívoco e da obscenidade numa mesma composição.

Enumeram-se ainda, nesse tratado de poética, outras categorias sarcásticas: os joguetas d'arteiro, as cantigas de seguir, a própria tençäo lírica, com ressaibos de chacota e as risadilhas. Joguetes d'arieiro eram velhos escarnhos de cunho popular. Constitulam as cantigas do seguir (não de segrel, como pretendia Tebfilo Braga) uma espécie de paródia, ou melhor, um novo tratamento, próprio e peculiar, de antigos tópoi, quer da poesia popular e tradicional, quer de poetas individualmente conhecidos. A tençäo, debate sobre qualqueri assunto, assumiu entre nós caráter preferencialmente satírico. Espécie de desafio, punha à prova a habilidade técnica e a agil'dade mental dos cor:tendores. No concernente às tenções, assim reza o tratado poético:

"Outras cantigas fazen os trobadores que chaman tenções, porque son feitas per maneira de razon que un haja contra outro, en que diga aquelo que por ben tever na prima ccbra e o outro responda-lhe ria outra dizendo o contrário. Estas se poden fazer d'amor, d'amigo, ou d'eseárnio, ou de maldizer, pero que deven de seer de mee<estria>" (cap. XII).

A cantiga de risadilha era assim denominada porque, consoar:te o tratadista anônimo, "rien ende às vezes os homens, mais non son cousas en que sabedoria nen outro ben haja", e que me pare- 
ce ancestral e típica representante da chalaça lusitana.

A disposição lírica e a atitude mordaz (já foi visto) formam traços dominantes, notas características da literatura portuguesa. Não se estranhe, pois, que a fusão desses dois elementos se manifeste, de maneira patente, desde os primórdios da poesia trovadoresca. Dai se compreende também a razão de alguns cantares d'amor a d’amigo se constituírem verdadeiros escárnios d'amori aliás, nas cantigas d'amigo, como é sabido, perpassam muitas vezes notas iroricas e travessas, de encantadora malicia: leia-se, por exemplo, a saborosa composição de Airas Nunes (CA 259). Ridicularizar as dóas, "presentes que os namorados trocavam entre si", (LAPA 307); decantar uma dona fea, velha e sandia (LAP9 203); chasquear do surrado tema morrer d'amor (LAPA 382); parodiar o talhar preits, "comtinar, prometer", useiro e vezeiro, nas cantigas d'amigo, (LA:A 385) ou fazer chacota da moça taful que punha branqu' e vermelho (LAPA 373) - são assuntos explorados por poetas de categoria de Pedro Amigo de Sevilha, João Garcia de Guilhade, Pero Garcia Burgalês e Pero Armea. E João Airas de Santiago nos esboça uma. caricatura muito engraçada de um dos traços convencionais do amor cortês: a excelsitude da dona que provocava a um tempo adoração e medo em seus admiradores (LAPA 181). Não admira, pois, que Rodrigues Lapa tenha incluído no seu já citado livro especimes que poderiam ser classificados também como de amor ou de amigo."

Desenvolveu-se nà poesia occitânica um género de conteúdo cbjetivo, pragmático - o sirventês, termo proveniente do proven. çal sirven, "servidor", mais o sufixo - tese: sirventesc. Portanto, o sirventês era originariamente um canto composto por um servidor em homenagem ou proveito do seu senhor. Se na parte formal ele se assemelhava à canção, sua temática, ao contrário, era de cunho ritidamente moral e setírico.

Por meio do sirventês difundiam-se idéias, pessoas e direitos, animavam-se os cristãos ao combate por Deus, celebravam-se acontecimentos, proclamavam-se a excelência de certos princípios morais, e injuriavam-se inimigos ou adversários. A imprensa política de hoje tem no panfleito poético o seu !egítimo passado. ${ }^{1 "}$

J Estão neste easo, entre outras, as cantigas de n. ${ }^{\circ} 30,36,39,66,134,165,166,308$, 398, 405, 110, 412, $129 \ldots$

10 PIMPAO, A. J. C. Histórí de literatora portuguean. Comibra, Quadrante. 1047, v. 1. p. 132. 
Alnda que em nossos cancioneiros se encontrem alguns cantares escarninhos motivados por acontecimentos históricos ou sociais, os escarnhos galaico-portugueses não atingem, nem de longe, a amplitude de conteúdo e os acentos graves e proféticos dos sirventeses morais e políticos da Provença. Para se ter uma idéia dessa espécie satírica occitânica, basta ler o sirventês do jogral gascão Marcabru, a propćsito da cruzada contro Almeria. ${ }^{11}$

Como exemplos de sarcasmos políticos, temos as contundentes canções sobre a traição dos alcaides de Sancho II, que entregaram os castelos ao usurpador, o conde de Bolonha, mais tarde, Afonso III. A felonia e a corrupção de fidalgos e prelados acendem a ira de poetas como Airas Vuitoron (LAPA 73-75 e 78-79), Diogo Pezelho (LAPA 98), Afonso Mendes de Besteiros (LAPA 61), Afonso Lopes da Baião (LAPA 57). Também D. Afonso $X$, trovador de altus predicados, servindo-se da língua minhoto-duriense para suas obras poéticas, contribuiu para o acervo das cantigas d'escárnio e maldizer com 35 composições, alguns de caráter sócio-político. Nestas, o rei de Leão e Castela traz à baila, as profundas dissençōes havidas entro ele e seu irmão, o infante D. Henrique (LAPA 34 e 35); parece oludir a suas malogradas pretensões à sucessão do Sacro Império Germânico (LAPA 33); não poupa remoques irônicos e violentos à deserção e à covardia de muitos ricos homens que se esquiva; vam, ou pelo menos, faronejavam, "hesitavam", quando se tratou de reprimir a revolta dos mouros andaluzes (LAPA 2, 16, 24 e 26); numa cantiga plena de movimento, moteja de seus coteifes que na refrega de Alcalá estavam "tremendo sen frio ant'os mouros d'Azamor" (LAPA 21).

O mundo às avessas é a temática de um engenhoso escárnio, misto de sirventês político-moral e de sátira pessoal, de João Soares Coelho: 0 imperador se insurge contra Roma, transforma-se em cruzado o mouro e o pagão João Fernandes em peregrinação a Terro Santa vai (LAPA 230). Voltando ao velho tema ciceroniano de - tempora, o moras, apresenta-nos o clérigo Martim Moxa uma vis5o pessimista e anti-crística do mundo: discórdias, ambiçōes, vilezas; carência de honra e de autoridade; venalidade dos áuilicos e onipotência da lisonja; pobreza generalizada; desaparecimento do ambiente culto, cortês e alegre - a crerezia; o triunfo do mal:

\section{"Já de verdade}

11 Ce. PIMPXO, r. 1, p. 114-5. 


\section{nen de lealdade \\ non ouço falar, \\ ca falsidade, mentira e maldade}

non this dá lugar" (LAPA 280).

E Pero Gomes Barroso, fidalgo porfuguês residente em Castela, não se conformando com o modus vivendi da época, extravasa o seu desencanto pela vida e pelos homens:

\section{"Ca vej'agora o que runca vi \\ e ouço cousas que nunca oí" (LAPA, 388).}

Airas Nunes legou-nos belo exemplar de sirventês moral, que tem por assunto a ausência da verdade: o poeta não mais a encontra (pro dolorl) nem nos moesieiros dos frades regrados, nem em Cistel e nem em Santiago (LAPA 69). E Gil Peres Conde retrata-nos em tonalidade escura a falta de amor fraterno onde justamente mais deverá existir: na corte, nas pousadas dos privados, nas tenaas dos infanções e, sobretudo, nas casas dos prelados e dos freire: tempeiros espitaleiros (LAPA 161). Aliás, causa-nos espanto a, atitude anti-clerical, o espírito erasmiano (avant la lèttre), o deboche as coisas sacras, a heterodoxia, em suma, que pervadem uma quarentena de nossas cantigas de escárnio. Chasqueia-se sem piedado dos membros do clero e das o:dens religiosas; uma crítica mordaz e crua atinge a todos, do simples clérigo ao papa, do frade ao frior, da freira à abadessa. Numa ironia contundente. ataca o jogral Diogo Pezelho as excomunhões que arcebispos e bispos, tangidos pela ambição do mando, fulminavam contra alcaides de $D$. Sancho II que teimassem em não entregar os castelos ao usurpador Afonso IV (LAPA 98). Misturava-se, com extrema desenvoltura, 0 sagrado e o fescenino; a esse respeito, leia-se a atrevida composição de Afonso Eanes do Coton (LAPA 37). Também não faltam pilhérias sobre a penitência ou confissão: João Baveca diz-nos, galhofeiramnte, que a soldadeira Maior Garcia sempre vivia assistida, nas suas andanças, por três clérigos pois não queria morrer sem confissão (LAPA 190) e João Vasques apresenta-nos Maria Leve ajoelhada aos pés do confessor para contar-lhe, numa atitude bem feminina, que não eram tantos os pecados que a atormentavam, mas sim a velihce que chegara implacavelmente:

"Sempr' eu pequei i, des que fui foduda;

pero direi-vos per que son perduda:

Sõo velh', ai, capelon!" (LAPA 247). 
Atacam-se, veladamente embora, os perdóes, isto 6 , as indul. sências e os favores espirituais obtidos por dinheiro, mais tarde profligados de maneira frontal por Lutero. De uma cruzada, em terras de ultramar viera a soldadeira Maria Peres, a famosa Balteire, carregada de perdões, mas a sua maeła (baú) não tinha cadeado e os moços roubaram-lhe todas as indulgências, de maneira que ela se viu obrigada a voltar ao antigo pecado... E conclui Pero da Ponte sua saborosa composição com esta vibrante estocada:

"Atal perdon ben se devia perder, ca muito foi cousa mal gaanhada" (LAPA 358).

A presença de Deus em nossas cantigas medievais toma os mais variados aspectos: vai da ação de graças aas impropérios pesadissimos assacados contra Deus. Contudo, ainda não se estudou suficientemente a blasfêmia e a heresia em nossos cancioneiros. Existem referências, ao menos indiretas, a canções imprecatórias e heréticas no escarnho de Afonso $X$ dirigido a Pero da Ponte:

"Vós non trobades come proençal, mais come Bernaldo de Bonaval; por ende non é trobar natural, pois que o del e do dem' aprendestes.

$E$ ben vej'ora que trobar vos fal, pois vós tan louca razon cometestes" (LAPA I7).

O trobar ao natural equivale ao trovar ao divino, representado pelas Cantigas de Santa Maria, no sentido ortodoxo a que chegou - poesia occitánica depois da cruzada contra os albigenses; opõe-se co trovar b!asfematório e satânico em que eram useiros e vezeiros os vagantes ou goliardos. Verbera aqui o Rei Sábio - que nas suas composiçōes sacras contou-nos para escarmento, muitas histórias de sacrifilégios e crimes nefandos contra, a religião - algumas cantigas, infelizmente perdidas, de Bernardo de Bonaval e Pero da Ponte, segréis de vida desbragada, que facilmente usavam das coisas santas para suas chocarrices. Como exemplo de revolta contra Deus, ai está o cavaleiro Pero Goterres a censurar duramente o Onipotente por ter dado ao amante uma coifa insuportável (LAPA 386). Numa linguagem audaciosa e provocante, Gil Peres objurga a Cristo p.orque, rival desleal, levou a bem-amada para o convento (LAPA 164 e 165). Mas é Pero Garcia Burgalês que atinge 0 auge dos impropérios heréticos. Increpa a Deus por lhe der roubado "quanio ben en-no mundo atendia", vale dizer, a perda da mulher amada, irrompendo em horrendas blasfêmias que, mesmo tomadas como 
atitude humorística, bem atestam o grau de liberdade a que então se chegou em matéria religiosa:

“Mais, en quant'éu já vivo for ,poren

non creerei que o Judas vendeu

nen que por nós na cruz morte prendeu

nen que filh' este de Santa Maria.

E se el aqui houvessss'a viver

e th'eu poren podesse mal fazer, per bõa fé, de grado tho farial" (LAPA 388).

Desde o século XVIII vai-se processando em Portugal uma grande transformação social: defauperada pelas guerras e pelo luxo, a nobreza entra em franca decadência; enquanto a burguesia, espaldada em suas melhores condições econômico-financeiras, torna-se cada vez mais poderosa e influente.

"O burguês, que é sobretudo o grande mercador, procura libertar-se da categoria de vilão em que se encontra, ascender à cavalaria ou, pelo menos, assumir lugar próprio e à parte". ${ }^{12}$

"Ao abrigo dos seus forais, que lhes garantiam as liber. dades, protegidos pelos reis, que buscavam abater a nobreza de sangue, os centros de vida burguesa prosperavam, enquanto as classes privilegiadas, os infanções e até ricos-homens, vegetavam, necessitando de acostar-se à munificiência régia e até mesmo à generosidade dos municipios". ${ }^{13}$

Dai se compreende facilmente que quase uma centena de escamhos tenha por tema o empobrecimento dos ricos-homens, a penúria dos infanções e a fome dos cavaleiros de linhagem. Pena $\dot{e}$, porém, que ainda não se tenha estudado convenientemente, além, das fundamentais Notas marginais de Michaelis ${ }^{14}$, tão precioso documentário sobre a decadèncias da nobreza lusitana nos séculos XIII e XIV. Pero da Ponte, o notável segrel das cortes de Fernando III e Afonso $X$, é que excele nos sarcasmos contra os ricomes es infançōes: leia-se, por exemplo, o saboroso escárnio (LAPA 353).

12 MARQUES, A. H. O. A mociedade medieval portugueas. Lisbon, Sá da Coata, 1964. p. 8. 1. LAPA. Licíes .... p. 196-1976.

11 VASCONCELOS, C. M. Randglossen xum altportugiesischen Liederbuch III. Vom Mittargbrod hispinischer Könige. Zeitschrift für romanische Pbilolozie, Halle, 25 :14967. 1901 . 
São escassas, porém as composições que versam assuntos mais gerais. Aliás, cabe ressaltar que a poesia lusa, tanto a lírica como a satírica, presa ao terra-a-terra do irdividual e circunstancial, sempre se dirigiu mais às pessoas que às instituições; apenas abrem exceção alguns poetas com acentuada vocação para o contemplação metafísica e que encarnando, por isso mesmo, a problemática do homem eterno, transcendem tempo e espaço: Camōes, Bocage, Antaro de Quental, Fernando Pessoa, entre outros. Em compensaçäo, abundam em nossos cancioneiros as sátiras de costumes que, numa lınguagem crua, debochada e fulminante, exploram com intenção trocista escândalos, vícios e defeitos de todas as classes e profissões. Essa face do gênio poético galaico-português ilustra com traços vigorosos as injustiças e as corrupções da época. Entretanto, essas chacotas "sociais", às vezes um pouco aveludadas pelo trocadilho chistoso e pela ambigüidade, possuem na sua maior parte conotações pessoais, levam endereço certo e contém referências tão cla. ras e concretas "que se podem logo alcançar con o dedo", na expressiva fraseologia, da composição documental de Estêvão da Guarda (LAPA 112). E, assim, ante a, nossa mente estupefala perpassa uma infinda procissão grotesca: um papa politiqueiro, prelados simoríacos e crápulas, clérigos dissolutos e frades mulherengos, abadesas desregradas e freiras condescendentes, falsos romeiros, reis espoliadores e pusilânimes, alta nobreza corrupta e decadente, ricoshomens avarentos e famélicos infaņ̧ōes, cavaleiros leprosos, judeus usurários, rábuias e juizes peitados, médicos incompetentes, desastrados astrólogos, velhos metidos a "gostosões", criadas inirigantes; raptadores e raptadas, adúlteras, homens e mulheres portadores de inconfessáveis taras e inazelas sexuais, ladrões de igrejas e conventos, cavalos lazarentos... Mas, scima de todo, as cantigas de maldizer nos oferecem uma galeria de quadros, ao mesmo tempo ousados e facetos, da vida e boêmia jogralesca. As aventuras mais frascórias entre jograis e soldadeiras, as mais escabrosas intimidades de alcova exurgem às escâncaras, num léxico obsceno, que hoje nos espanta pela naturalidade e, até, pela atualidade do seu uso. ${ }^{1 s}$

Também põe-se às claras, nestes cantares escarninhos, um problema típico da vida trovadoresca: as querelas entre jograis e trovadores, isto $e$, aqueles, teoricamente meros executores de composições alheias, quando se punham a compor palavras e sons, forcejavam por subir de degrau nesso hierarquia do trovadorismo de

15 Ce. SARAIVA, A. J. \& LOPES, O. História da literatura portaguese. 7. ed. Santos, Martins Funted, 1973. p. 65. 
inspiração provençal; porém, essa pretensão, porque fronialmenie contrária à rígida estratificação sócio-artística da época, não podia deixar de provocar melindres e ciúmes por parte dos trovadores e segréis.

Como se vê, constituem as cantigas d'escárnio e de maldizer valioso documento para a compreensão da nossa vida medieval. E embora a, sua linguagem seja muitas vezes desabusada e escatologica, representam, todavia, raro valor, não só lingüistico mas tam. bém histórico e social.

\section{REFERENCIAS BIBLIOGRAFICAS}

1 ALFONSO $X$, el Sábio. Las siete partidas: cotejadas con varios codeces antiguos por Ia Real Academia de la Historia. Madrid. Irapr. Real, 1807.

2 FONSECA, F. V. P. Cantigas de escirnio e maldizer dos trovadores galego-portague ses. Lisboa, Livr. Clissica, 1961.

3 FRAPPIER, F. V. P. Sur un procès fait à l'amour courtois. Romania, Parfa, 93(2): 145-93, 1973.

4 LAPA, M. R. Cantigas d'escarhoro e de mal dizer dos cancionoiris galego-portugueses. 2. ed. Vigo, Ed. Galaxia, 1970.

5 s. ed., 1929.

6 Liçōes de literatura portuguess; época medieval. 8. ed. Colmbra, Coim. bra Ed., 1970.

7 MARQUES, A. H. O. A sociedade medieval portuguess. Lisboa, Sá da Costa, 1964.

8 PIMPAO. A. J. C. História da literatara portugnesa. Coimbra, Quadrante, 1947, จ. 1.

9 SARAIVA, A. J. \& LOPES, O. História da literatura portuguesa. 7. ed. Santos, Martins Fontes, 1973.

10 SPINA, S. O "fazer bem" dos cantares trovadorescos. Revista Braslleira de Filologia, Rio de Janeiro, $2: 179-86$, dez. 1956.

11 VASCONCElos, C. M. Cancioneiro da Ajuda. Ed. critica e comentada. Halle, $\mathbf{M}$. Niemeyer, 1904, v. 1.

12.

- Randglossen zum altportugiesischen Liederbuch III. Vom Mittagbrod hispanischer Könige, Zeitschrift für romanische Philologie, Halle, 25:149-67, 1901.

\section{RESUMO}

De início, reflete o autor sobre o caráter dualístico e aparentemente contraditório do nosso trovadorismo medieval: as cantigas d'amor e d'amigo ao lado das cantigas d'escárnio e maldizer.

Aborda, a seguir, as diferentes espécies da sátira galega-portuguesa, sobretudo o sirventês moral e político, para debater-se no problema das cançōes blasfemas e heréticas e nos escarnhos contra. o empobrecimento dos ricos-homens e dos infançöes.

Termina com uma rápida visãc das sátiras "sociais": exploração, com intençōes trocistas, dos escândalos, vícios e mazelas de todas as classes sociais da época, principalmente dos jograis e das soldadeiras. 


\section{RESUME}

L'auteur réfléchit d'abord sur le caractère dualiste et apparemment contradictoire de la production des troubadours portugais: les cantigas d'amor et d'amigo à côté des cantigas d'escárnio et de maldizer. Ensuite, l'auteur envisage les différentes espèces de la satire luso-galicienne, surtout le sirventês moral et politique, ce qui mène au problème des chansons blasphématoires et hérétiques, et aux escarnhos contre l'appauvrissement des ricos-homens et des infançōes.

L'article finit par une brève revue des satires "sociales": l'exploitation, avec des intentions railleuses, des scandales, des vices et des soillures de toutes les classes sociales de l'époque, notamment cles jongleurs et des soldadeiras. 